\title{
Dynamics of Surface Exchange Reactions Between Au and Pt for HER and HOR
}

\author{
Abrams, Billie; Vesborg, Peter Christian Kjærgaard; Bonde, Jacob Lindner; Jaramillo, Thomas; \\ Chorkendorff, Ib
}

Published in:

Journal of The Electrochemical Society

Link to article, DOI:

10.1149/1.3040509

Publication date:

2009

Document Version

Publisher's PDF, also known as Version of record

Link back to DTU Orbit

Citation (APA):

Abrams, B., Vesborg, P. C. K., Bonde, J. L., Jaramillo, T., \& Chorkendorff, I. (2009). Dynamics of Surface Exchange Reactions Between Au and Pt for HER and HOR. Journal of The Electrochemical Society, 156(2), B273-B282. https://doi.org/10.1149/1.3040509

\section{General rights}

Copyright and moral rights for the publications made accessible in the public portal are retained by the authors and/or other copyright owners and it is a condition of accessing publications that users recognise and abide by the legal requirements associated with these rights.

- Users may download and print one copy of any publication from the public portal for the purpose of private study or research.

- You may not further distribute the material or use it for any profit-making activity or commercial gain

- You may freely distribute the URL identifying the publication in the public portal 


\title{
Dynamics of Surface Exchange Reactions Between Au and Pt for HER and HOR
}

\author{
Billie L. Abrams, ${ }^{\text {a,z }}$ Peter C. K. Vesborg, ${ }^{\text {a Jacob L. Bonde, }}{ }^{\text {b }}$ \\ Thomas F. Jaramillo, ${ }^{c, *}$ and Ib Chorkendorff ${ }^{\mathrm{a}, *}$ \\ ${ }^{a}$ Center for Integrated Nanoparticle Functionality, Department of Physics, NanoDTU, Technical University \\ of Denmark, 2800 Kongens Lyngby, Denmark \\ ${ }^{b}$ IRD A/S, Kullinggade 31, DK-5700, Svendborg, Denmark \\ ${ }^{c}$ Department of Chemical Engineering, Stanford University, Stanford, California 94305, USA
}

\begin{abstract}
Cyclic voltammetric analysis of the Pt-on-Au system for hydrogen evolution and oxidation reactions (HER/HOR) indicates that dynamic surface exchange reactions occur between Pt and Au. HER/HOR activities depend on the dominant surface species present, which is controllable by the potential applied to the system. Bulk Au is not very active for HER/HOR; however, when Pt is deposited onto the Au surface, the system becomes active. The Pt-on-Au system can subsequently be deactivated by cycling to potentials cathodic of the $\mathrm{OH}$-adsorption and Pt-dissolution potentials $(\sim+1.18 \mathrm{~V}$ vs normal hydrogen electrode, $\mathrm{NHE}$, at $\mathrm{pH} 0)$. Following deactivation, the system can be reactivated by cycling above this potential, giving an activation potential of $\sim+1.0 \mathrm{~V}$ vs NHE. This deactivation/reactivation can be cycled repeatedly and occurs for various forms of the Pt-on-Au system. This potential-dependent surface exchange reaction is attributed to the lower surface energy of Au relative to Pt causing Au to migrate to the surface. When the system is deactivated, Au is present at the surface. However, Pt migrates back to the surface at higher positive potentials, where $\mathrm{PtO}_{x} / \mathrm{PtOH}_{x}$ is formed, leading to adsorbate-induced surface segregation. The surface compositions were verified by X-ray photoelectron spectroscopy. Implications for electrocatalyst materials development for polymer electrolyte membrane fuel cells are discussed.
\end{abstract}

(C) 2008 The Electrochemical Society. [DOI: 10.1149/1.3040509] All rights reserved.

Manuscript submitted September 18, 2008; revised manuscript received November 7, 2008. Published December 15, 2008.

In the search for inexpensive, stable, yet active electrocatalysts for the hydrogen evolution reaction (HER) and hydrogen oxidation reaction (HOR), alloy or core-shell materials/nanoparticles are promising candidates. The collective properties of such alloy or core-shell systems can potentially be superior compared to their individual components. This is important when considering Pt-based alloys or core-shell structures where the amount of Pt needed to maintain high activity is to be minimized. A combined Pt-M (where $\mathrm{M}$ is another metal) system could serve two purposes: to minimize the amount of expensive Pt present in the system while maintaining high activity and to stabilize $\mathrm{Pt}$ against dissolution ${ }^{1}$ or detrimental reactions such as $\mathrm{CO}$ poisoning. ${ }^{2-4}$

Recently, computational methods have been utilized to aid efforts in screening candidate materials for specific catalytic reactions such as the HER. ${ }^{5}$ Using density functional theory (DFT) and combining many criteria including catalytic activity and stability, Greeley et al. ${ }^{5,6}$ demonstrated the ability to predict potential surface alloy candidates such as Pt-Bi with a high activity for HER. This activity was subsequently verified experimentally. ${ }^{5}$ Although the Pt-Bi system is promising, it still contains $\mathrm{Pt}$ as the majority component. Because $\mathrm{Pt}$ is a scarce element, it is desirable to investigate systems where the Pt content is minimized. Several other Pt-based surface alloy materials were also selected as potential candidates by Greeley et al. including Pt-Au-based systems.

The Pt-Au system has been analyzed by many groups for various catalytic reactions. For example, $\mathrm{Pt}-\mathrm{Au}$ alloys have been reported to be more active for ethylene glycol oxidation ${ }^{7}$ as well as methanol oxidation $^{8-11}$ relative to pure Pt. In most cases, the form of the $\mathrm{Pt}-\mathrm{Au}$ alloy, whether in an alloy form or overlayer/core-shell structure form, as well as the relative ratios of each component affect the level at which these systems perform.

Zhang et al. ${ }^{1}$ reported that gold clusters deposited onto the surface of $\mathrm{Pt}(111)$ had a stabilizing effect against Pt dissolution for the oxygen reduction reaction (ORR). They studied the oxidation and reduction cycles for $\mathrm{Pt}$ under conditions where $\mathrm{Pt}$ dissolution is likely to occur, +0.6 to $+1.1 \mathrm{~V}$ vs the reversible hydrogen electrode, due to $\mathrm{PtOH}$ and $\mathrm{PtO}$ formation. The dissolution mechanism here is associated with the oxidation of $\mathrm{Pt}^{0}$ to $\mathrm{Pt}^{2+}$. Based on the

\footnotetext{
* Electrochemical Society Active Member.

${ }^{\mathrm{z}}$ E-mail: billie.abrams@fysik.dtu.dk
}

Pourbaix diagrams ${ }^{12}$ for $\mathrm{Pt},+1.18 \mathrm{~V}$ vs the normal hydrogen electrode $(\mathrm{NHE})$ is the theoretical corrosion potential at $\mathrm{pH} \sim 0$. This correlates with the formation of $\mathrm{PtO} / \mathrm{Pt}(\mathrm{OH})_{2}$ in an aqueous environment. The effects of alloying or the addition of impurity metal atoms could alter this dissolution potential as observed specifically for the ORR reaction. ${ }^{1}$

Friedrich et al. analyzed the effects on $\mathrm{CO}$ oxidation of Pt particles with varying sizes deposited on a Au substrate. ${ }^{13,14}$ They report that deviation from bulk Pt behavior for the small Pt nanoparticles studied could be dependent upon size and possibly also on catalyst-support interactions. The main conclusion for the behavior observed focused on geometric structural effects which could also be dependent upon the choice of substrate, in this case Au.

A clear interaction between $\mathrm{Au}$ and $\mathrm{Pt}$ and its effect on catalytic reactivity was demonstrated by Pedersen et al. ${ }^{15}$ They reported stronger CO binding on $\mathrm{Pt}$ when it was deposited as an overlayer on a $\mathrm{Au}(111)$ substrate. This increase in reactivity for $\mathrm{CO}$ on $\mathrm{Pt}$ was attributed to the correlation between adsorbate binding energy changes with a shift in the position of the Pt overlayer d-band center. An important consideration taken into account in this work was how surface segregation energies affected the adsorbate binding properties. ${ }^{15}$ Pedersen et al. also reported that a randomly mixed $\mathrm{Au}-\mathrm{Pt}$ layer at the surface is not thermodynamically stable in ultrahigh vacuum (UHV) due to the lower surface free energy of $\mathrm{Au}$. Thus, there is a driving force for the Pt to diffuse away from the surface and into the bulk, leaving a thin Au layer present on the surface.

In the present work, a systematic study of $\mathrm{Pt} / \mathrm{Au}$ surface segregation to form alloys or overlayer structures on $\mathrm{Au}$ foils and nanoparticles was performed. The Pt-on-Au system is used to demonstrate the relationship between applied potential, HER/HOR activity, chemical potential of adsorbates, and materials stability in relation to segregation energies. When $\mathrm{Pt}$ is deposited onto the surface of $\mathrm{Au}$, the system becomes active for HER and HOR. However, it is found that potential-dependent surface exchange reactions between $\mathrm{Au}$ and Pt determine which material is in fact participating in either HER or HOR. The initial attempts to minimize the amount of Pt while at the same time capitalizing on its high HER and HOR activity were counteracted by the fact that, due to a lower surface free energy, ${ }^{15-17}$ $\mathrm{Au}$ remains the dominant surface species at potentials cathodic of $\sim+1 \mathrm{~V}$ vs NHE. This may, however, in turn be counteracted by the chemical potential of adsorbates. This is, for example, observed 
when exposing a $\mathrm{Cu}-\mathrm{Ni}$ system to $\mathrm{CO} .{ }^{18} \mathrm{Here}, \mathrm{Cu}$ will be at the surface under UHV conditions, while Ni will be brought to the surface in a $\mathrm{CO}$ atmosphere. In the $\mathrm{Au}-\mathrm{Pt}$ system, $\mathrm{Pt}$ is again pulled to the surface when potentials equal to or anodic of $\sim+1 \mathrm{~V}$ vs NHE are applied in both electrochemically aqueous or fuel cell environments. At these higher potentials, it is thought that adsorption of $\mathrm{OH}$ groups leads to the formation of $\mathrm{PtO}_{x}$ or $\mathrm{PtOH}_{x},{ }^{19,20}$ causing $\mathrm{Pt}$ to migrate back to the surface. Pt may also be brought to the surface when the system is exposed to air due to the formation of $\mathrm{PtO}_{x}$. It is thus seen that the surface composition can be controlled by applied potential in combination with adsorbate induced processes.

\section{Experimental}

Materials synthesis and electrode preparation.-Bulk Au foil.$\mathrm{Au}$ foil (0.1 mm thick) with a purity of $99.99 \%$, metals basis was utilized. A strip $(5 \times 2 \mathrm{~cm})$ was sonicated in an ethanol/water mixture for $1 \mathrm{~h}$ followed by sonication in Millipore $\mathrm{Q}$ water for $1 \mathrm{~h}$. It was then rinsed with Millipore Q water and dried in air. The Au foil was used directly as an electrode in this cleaned form.

Bulk Au foil was studied using the three-electrode electrochemical cell. A baseline cyclic voltammogram $(\mathrm{CV})$ was measured for the $\mathrm{Au}$ foil by using a $\mathrm{Au}$ foil counter electrode (CE) and cycling between -0.35 and $+1.6 \mathrm{~V}$ vs the saturated calomel electrode (SCE) at a $\mathrm{pH} \sim 0.3$ to 0.4 (corresponding to -0.085 to $+1.87 \mathrm{~V}$ vs NHE) at $50 \mathrm{mV} / \mathrm{s}$. This was done until a stable $\mathrm{CV}$ was obtained prior to performing further experiments or depositing Pt onto the surface. This stabilization occurred typically after 10-20 cycles. The typical features of $\mathrm{Au}$ redox behavior in a $0.5 \mathrm{M} \mathrm{H}_{2} \mathrm{SO}_{4}$ electrolyte were visible, with the characteristic $\mathrm{Au}$ reduction peak present at about $+1.15 \mathrm{~V}$ vs NHE. ${ }^{21-23}$

Gold nanoclusters. - Gold nanoclusters were synthesized using an inverse micelle method. ${ }^{24-26}$ As-synthesized and in solution phase, these clusters were $1.6 \pm 0.2 \mathrm{~nm}$ as determined by transmission electron microscopy (TEM) (not shown). The Au nanoclusters were drop-cast onto Toray carbon paper to form an electrode. The amount of Au clusters deposited onto the carbon paper was held constant at $20 \mu \mathrm{L}$ of $5 \times 10^{-4} \mathrm{M}$ solution $(10 \mathrm{nmol} \mathrm{Au})$. Assuming the packing arrangement leading to stable magic-sized clusters ${ }^{27}$ of 55 atoms in a $1.6 \mathrm{~nm}$ cluster, this volume $(20 \mu \mathrm{L})$ corresponded to $1.1 \times 10^{14}$ clusters and a surface area of $8.8 \mathrm{~cm}^{2}$. If a spherical geometry is assumed, then 127 atoms $/ 1.6 \mathrm{~nm}$ Au cluster led to $4.7 \times 10^{13}$ clusters. This corresponded to a surface area of $3.8 \mathrm{~cm}^{2}$. However, due to the nature of this synthesis process, there are organic ligands (surfactants) present on the cluster surface. In an attempt to remove these surfactants, the Au clusters were baked at $300^{\circ} \mathrm{C}$ for $2 \mathrm{~h}$ in air. This, of course, led to significant sintering of the particles. The cluster size was roughly estimated to then be on the order of $10 \mathrm{~nm}$ based on the shift in the surface plasmon in the UV-visible absorption spectrum measured on a transparent substrate, fluorine-doped tin oxide (FTO). The size distribution is surely also altered; however, it is difficult to obtain a better estimate because TEM cannot be performed on the samples once they have been deposited onto the substrate. Thus, the geometric surface area of the Au cluster sample changed significantly to $\sim 0.6 \mathrm{~cm}^{2}$.

E-TEK Au on XC-72 carbon powder.- E-TEK Au nanoparticles supported on XC-72 carbon powder were purchased from E-TEK. These particles, with a $20 \%$ loading, typically have a particle size of 20-30 $\mathrm{nm}$ based on information provided by E-TEK. The E-TEK Au particles $(20 \mathrm{mg}$ ) were mixed into a 2.5:1 ethanol (96\%): Nafion (5\% in ethanol) slurry and drop-cast onto a Toray carbon paper gas diffusion layer (GDL). Depending on the size, the total number of E-TEK Au particles was $\sim 1.4 \times 10^{12}$ (for $30 \mathrm{~nm}$ particles) and $\sim 4.9 \times 10^{12}$ (for $20 \mathrm{~nm}$ particles), yielding theoretical Au surface areas of $\sim 40$ and $61 \mathrm{~cm}^{2}$, respectively. The gold reduction peak for these particles gave an area of $150 \mathrm{~cm}^{2}$ (see the area determination approach under the section "Cyclic voltammetry"), suggesting that there may be smaller particles also present in the size distribution. $\mathrm{Pt}$ was deposited onto the E-TEK Au/C-paper system electrochemi- cally from a (99.99\%) Pt mesh CE (see the deposition method in the Electrochemistry section below) and the entire sample was then pressed into a membrane electrode assembly (MEA) following a procedure similar to that of Chakraborty et al. ${ }^{28}$ The MEA assembly involved cutting the GDL containing the E-TEK Au-Pt catalyst sample into a $2 \mathrm{~cm}$ diameter circular electrode. A Nafion 117 electrolyte membrane was then sandwiched between the sample and an IRD Fuel Cells A/S Pt standard (also deposited onto a $2 \mathrm{~cm}$ GDL). This assembly was then pressed into the final MEA form at $\sim 135^{\circ} \mathrm{C}$ and 15 bar for $5 \mathrm{~min}$. The MEA was subsequently placed into a fuel cell measuring assembly (designed by IRD Fuel Cells A/S) consisting of two bipolar graphite plates with gas flow channels and water reservoirs allowing for humidification of the gases passing through these channels. In this configuration, the fuel cell was connected to a potentiostat and operated as an electrochemical cell.

Electrochemistry procedures. - Three-electrode electrochemical cell.- A three-electrode electrochemical cell was used to measure HER. The setup consisted of two open beakers. One beaker contained both the sample working electrode (WE) and the CE, while the second beaker housed the SCE; the two beakers were connected by an $\mathrm{Agar} / \mathrm{KNO}_{3}$ filled salt bridge to avoid contamination from the reference electrode. Depending on the type of experiment being run (see the Results section), the $\mathrm{CE}$ was interchanged between a $\mathrm{Pt}$ mesh, Au foil, or Toray carbon paper. Prior to use as a CE, the Pt mesh was electropolished in $0.5 \mathrm{M} \mathrm{HNO}_{3} /$ MilliporeQ water to oxidize away any organic contaminants, the Au foil was cleaned using sonication (as described above), and the C-paper was utilized as received. For all electrochemical reaction studies the electrolyte in both beakers was $0.5 \mathrm{M} \mathrm{H}_{2} \mathrm{SO}_{4}, T=25^{\circ} \mathrm{C}$, which was always deaerated with $\mathrm{N}_{2}$ for at least $20 \mathrm{~min}$, and the $\mathrm{pH}$ was measured after each experiment. Experiments were also performed in $\mathrm{HClO}_{4}$ for comparison but, because the general system behavior was similar to $\mathrm{H}_{2} \mathrm{SO}_{4}$, only these $\mathrm{H}_{2} \mathrm{SO}_{4}$ results are discussed. The potentiostat used was a multichannel VMP2 Princeton Applied Research potentiostat from Biologic.

In each sample case (Au nanoparticles, E-TEK $\mathrm{Au}$, and $\mathrm{Au}$ foil) Pt was deposited onto the surface electrochemically using anodic dissolution of $\mathrm{Pt}$ and $\mathrm{Pt}$ ion transfer from a Pt mesh $\mathrm{CE}$ to the surface of the Au WE. Using the Au sample as the WE, a Pt mesh as the CE, and an SCE reference electrode, the potential of the WE was swept at $50 \mathrm{mV} / \mathrm{s}$ during cyclic voltammetry to potentials greater than the corrosion potential for $\mathrm{Pt}\left(\sim+1.18 \mathrm{~V}\right.$ vs NHE) ${ }^{12}$ The potential applied to the WE was between -0.35 and $+1.6 \mathrm{~V}$ vs SCE, which, using an electrolyte with a $\mathrm{pH} \sim 0.3$ to 0.4 , ranged from $\sim$ -0.09 to $+1.87 \mathrm{~V}$ vs NHE. Activation could also be performed by just cycling between -0.35 and $+1.0 \mathrm{~V}$ vs $\operatorname{SCE}(\sim-0.1$ to $+1.27 \mathrm{~V}$ vs NHE). All potentials in this work are subsequently referenced to NHE.

This method of utilizing the Pt CE for depositing Pt relies on the potential applied to the $\mathrm{Pt} \mathrm{CE}$ while the WE is evolving hydrogen. The potential of the Pt CE is typically near $+1.87 \mathrm{~V}$ vs NHE when the WE is at $-0.09 \mathrm{~V}$ vs NHE. The deposition of Pt from a Pt CE onto a $\mathrm{Au}$ WE was observed early on by Brummer and Burrows ${ }^{29,30}$ to be potential-dependent. Thus, the use of a Pt CE was generally not recommended when using a Au WE. ${ }^{29,30}$ During deposition of the Pt from the CE, the HER current was monitored for an increase in activity. This is the activation process.

Once the sample was in the active state, the Pt CE was replaced by either a clean $\mathrm{Au}$ foil $\mathrm{CE}$ or a $\mathrm{C}$-paper $\mathrm{CE}$, the cell was cleaned, and the electrolyte was replaced by clean electrolyte (to rule out the electrolyte as a possible source of $\mathrm{Pt}$ ). The activated sample was then cycled in a mild potential window of -0.09 to $+0.47 \mathrm{~V}$ vs NHE. In this potential window a decrease in HER activity occurred and continued until the original activity of the plain $\mathrm{Au}$ foil was reached. This decay in HER activity was monitored over time. This is the deactivation process. 
Following the deactivation process, the anodic potential was then slowly ramped from +0.57 to $+1.87 \mathrm{~V}$ vs NHE while the HER activity increase was monitored while still using the Pt-free electrolyte and non-Pt CE This is the reactivation process.

Cyclic voltammetry. - Cyclic voltammetry was used to characterize the electrocatalytic activity of the samples and to deposit Pt onto the Au samples from the Pt CE source. The active area determination depended on the sample form and state (bulk Au foil, small $\mathrm{Au}$ nanoparticles, large standard E-TEK $\mathrm{Au}$ nanoparticles). In all cases prior to Pt deposition, the Au reduction peak could be utilized but a geometric area could also be utilized. The two areas were nearly always similar in value so, unless otherwise noted, for the $\mathrm{Au}$ foil samples prior to activation, the current density was determined using the Au reduction peak area. The Au reduction peak area was then subsequently normalized to a previously measured $\mathrm{Au}(111)$ single crystal with an area of $0.1 \mathrm{~cm}^{2}$ corresponding to $0.08 \mathrm{mC}$. In the case of the small gold clusters, the area was determined by utilizing their size, surface area, and volume deposited. When Pt was deposited onto the Au samples, the hydrogen under potential deposition (HUPD) region was used to determine the amount of Pt participating in the reaction. In this case the normalization factor utilized was $210 \mu \mathrm{C} / \mathrm{cm}^{2}$ for polycrystalline Pt. All measurements were made at room temperature.

Fuel cell operation.- As stated in the Synthesis section above, the E-TEK $\mathrm{Au}-\mathrm{Pt}$ nanoparticles were pressed into an MEA and inserted into a polymer electrolyte membrane (PEM) fuel cell measurement station. The PEM fuel cell was then operated as an electrochemical cell with the E-TEK Au-Pt side connected as the WE and a standard IRD Pt on XC-72 carbon powder as the CE By running pure hydrogen on the $\mathrm{CE}$ side of the MEA, the $\mathrm{CE}$ effectively becomes an NHE reference electrode in this two-electrode experiment. An inert gas such as argon (Ar) was used on the WE side to allow analysis of HER as well as specific features such as HUPD and other redox reactions during cyclic voltammetry or chronoamperometry. To study the HOR reaction, the gas on the WE side of the fuel cell was switched from $\mathrm{Ar}$ to $\mathrm{H}_{2}$. Under these conditions, HER could also be analyzed simultaneously. All fuel cell measurements were made at room temperature.

Materials characterization.-X-ray photoelectron spectroscopy (XPS) (Physical Electronics Industries) with a non-monochromated $\mathrm{Al} \mathrm{K} \alpha$ source was used to characterize the surface composition of the samples before and after electrocatalytic activity measurements. The scans were recorded with a pass energy of $50 \mathrm{eV}$, a step size of $0.2 \mathrm{eV}$, and $250 \mathrm{~ms} / \mathrm{step}$. Glancing angle measurements were performed to attempt to access the nearer surface region. Under these conditions, the sample was placed on a $42^{\circ}$ angle holder and the detector was rotated to a $0^{\circ}$ position vs the sample surface (as compared to the normal $180^{\circ}$ position) with a $90^{\circ}$ slit in place. This changed the analysis area and depth to be more surface sensitive, probing $\sim 5$ to $10 \AA$ instead of the normal $\sim 20$ to $30 \AA$.

TEM was used to image the size of the Au nanoclusters in the as-prepared state (not shown). The Au clusters are initially quite small in size at about $1.6 \pm 0.2 \mathrm{~nm}$. However, once deposited onto a C-paper substrate and annealed, the particles sinter, leading to much larger sizes, on the order of $\sim 10 \mathrm{~nm}$.

\section{Results and Discussion}

A Pt-on-Au system was produced in several forms as described in the Synthesis section above: $(i)$ bulk Au foil with Pt deposited onto the surface (ii) small ( $\sim 2 \mathrm{~nm})$ Au nanoparticles on C-paper sintered to $\sim 10 \mathrm{~nm}$ with $\mathrm{Pt}$ deposited on the surface, and (iii) E-TEK Au nanoparticles on C-paper with Pt deposited onto the surface. Initially the production of nanoparticles was motivated by the desire to increase the surface area-to-volume ratio as well as to capitalize on the unique surface sites present on nanoscaled materials. However, to examine the surface exchange reaction more closely, a bulk Pt-on-Au foil structure was studied in detail and used as the model system. In such a system, the isolation of important parameters is facilitated. The surface exchange reactions between $\mathrm{Pt}$ and $\mathrm{Au}$ occurred in all three systems.

Bulk Au foil.- To follow the surface exchange reactions between $\mathrm{Pt}$ and $\mathrm{Au}$, one large $(5 \mathrm{~cm} \times 2 \mathrm{~cm} \times 0.1 \mathrm{~mm}) \mathrm{Au}$ foil sample was prepared and divided into smaller pieces, allowing for a parallel series study. When using a C-paper CE, the normalized current density of the clean $\mathrm{Au}$ foil (using the Au reduction peak area) was $\sim 0.22 \mathrm{~mA} / \mathrm{cm}_{\mathrm{Au}}^{2}$ at room temperature at a potential of $-0.091 \mathrm{~V}$ vs NHE. This value includes contributions from both faradaic and nonfaradaic processes, suggesting that the clean Au foil is not very active for HER. Pt was deposited onto the large Au foil so that all pieces would begin with the same amount of Pt. This was done for two Pt layer thicknesses: a thin Pt layer $(\sim 5 \mathrm{ML}$ as per XPS depth profiling) and a thick Pt layer $(\sim 70 \mathrm{ML}$ as per XPS depth profiling). The thin Pt layer formed after approximately $7.5 \mathrm{~h}$ of cycling between -0.09 and $+1.87 \mathrm{~V}$ vs NHE as shown in Fig. 1a. To create the thicker layer, the cycling was continued for a total period of $24 \mathrm{~h}$, leading to a maximum current (see the CV inset of Fig. 1a), which coincides with a minimization of the $\mathrm{Au}$ reduction peak. At this point, the Pt film was visible to the eye as a gray discoloration of the Au surface.

Subsequent to the Pt deposition, the sample was divided into equal pieces, each smaller sample receiving different treatments. The treatment entailed electrochemical deactivation and reactivation processes designated by the potential window to which the sample was exposed. Following treatment, the sample surface was analyzed using XPS. Three processes could be delineated depending on the treatment procedure. Figure 1 outlines these processes for the thick Pt film case in terms of HER activity, XPS surface composition, and a proposed model based upon the data. The same processes were observed electrochemically using the thin Pt film. However, it was more difficult to obtain supporting XPS data on the thin Pt film sample due to the $\mathrm{Au} 4 \mathrm{f} \alpha 3$ and $\alpha 4$ peaks overlapping the same energies as the $\mathrm{Pt} 4 \mathrm{f}$ peaks. Both the $\mathrm{Au} 4 \mathrm{f}_{5 / 2}$ and the $\mathrm{Au} 4 \mathrm{f}_{7 / 2}$ have contributing $\alpha 3$ and $\alpha 4$ peaks lying at 9.8 and $11.8 \mathrm{eV}$, respectively, from the main peaks. For the $\mathrm{Au} 4 \mathrm{f}_{5 / 2}$ the $\alpha 3$ and $\alpha 4$ peaks lie at 77.85 and $75.85 \mathrm{eV}$, respectively. For the $\mathrm{Au} 4 \mathrm{f}_{7 / 2}$ peaks they are located at 74.2 and $72.2 \mathrm{eV}$. This leads to interference, particularly for the $\mathrm{Pt} 4 \mathrm{f}_{5 / 2}(74.25 \mathrm{eV})$ but also for the $\mathrm{Pt} 4 \mathrm{f}_{7 / 2}(70.9 \mathrm{eV})$. Thus, the thick Pt film was utilized to demonstrate the system behavior. The three processes are HER activation, HER deactivation, and HER reactivation. When the sample is in the active state, $\mathrm{Pt}$ is on the surface. In the deactivated state, Pt has migrated into the bulk and $\mathrm{Au}$ has come to the surface. This situation can then be reversed during reactivation by cycling to higher anodic potentials and leading to Pt migration again to the surface, replacing Au. This deactivation and reactivation process can be reproduced cyclically by altering the potential window. The details of the three processes are delineated in Fig. 1a-c.

Activation process. - Upon activation of the Au foil utilizing a Pt CE (as described in the Experimental section above) the sample becomes active. This is shown in the cyclic voltammetry data of Fig. 1a-i, where the increasing HER activity occurs when cycling between -0.09 and $+1.87 \mathrm{~V}$ vs NHE. For the thin Pt layer, the $\mathrm{Au}$ reduction peak is still present when cycling to potentials greater than $+1.2 \mathrm{~V}$ vs NHE; however, it is not present in the thick film, suggesting the surface is completely covered with Pt. This difference is illustrated when comparing the two CVs in Fig. 1a-i. The first set of $\mathrm{CVs}$ (corresponding to the main axis showing the arrow) shows the evolution of the thin Pt film. Here one can still see the Au reduction peak. However, the inset of Fig. 1a-i no longer shows this Au reduction peak and corresponds to the presence of a thick Pt film which can be seen by eye. Accordingly, XPS data (Fig. 1a-ii) show that the dominant species on the surface is Pt. These XPS spectra were normalized to the $\mathrm{Pt} 4 \mathrm{f}_{7 / 2}$ peak to highlight the changes in the $\mathrm{Au} 4 \mathrm{f}$ peaks to the $\mathrm{Pt} 4 \mathrm{f}$. To determine the ratio between the $\mathrm{Pt} 4 \mathrm{f}$ 


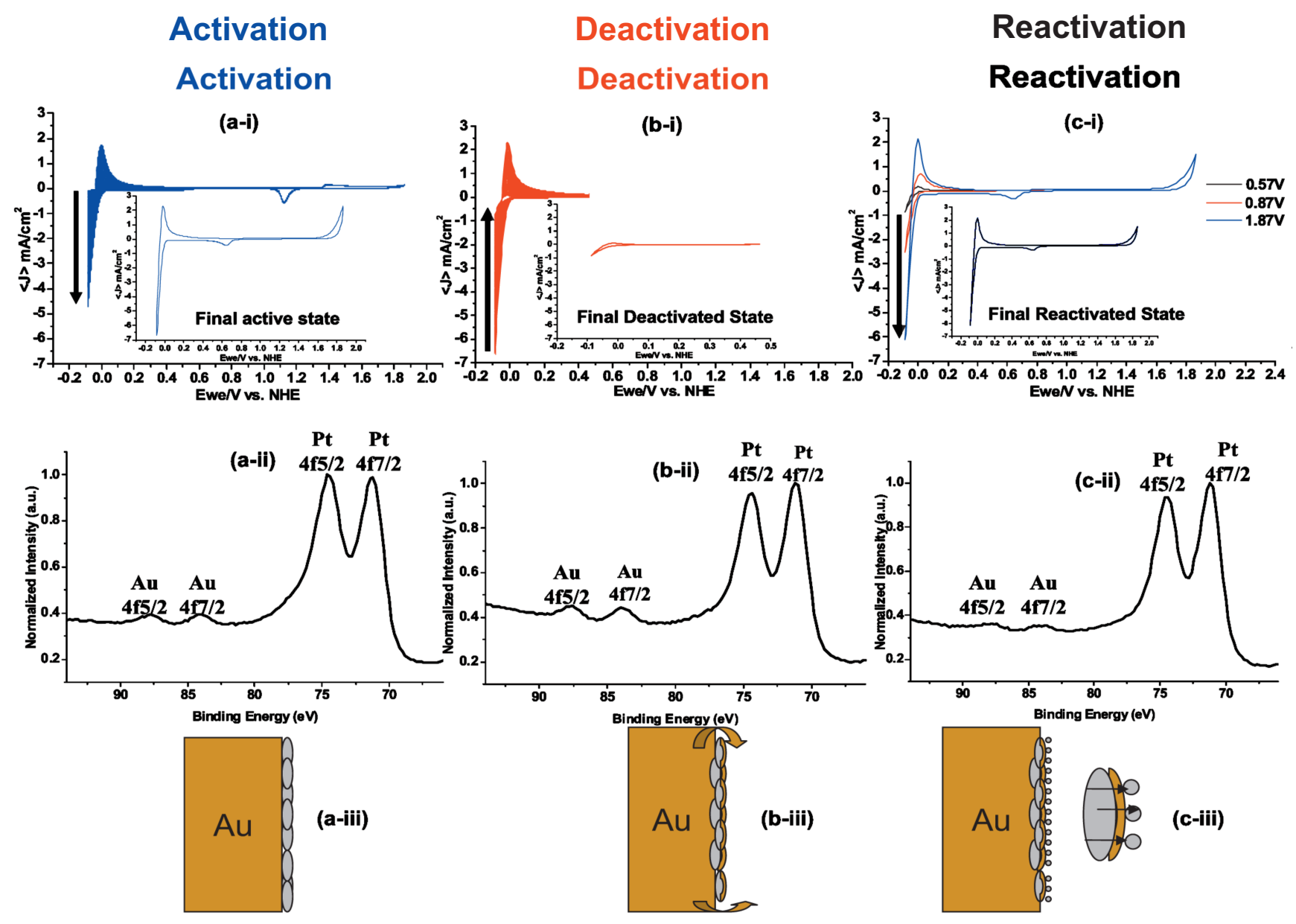

Figure 1. (a) (a-i) $\mathrm{CV}(\mathrm{CE}=\mathrm{Pt}, 50 \mathrm{mV} / \mathrm{s})$ showing activation (i.e., Pt deposition) of the Au foil using a Pt CE The main part of the figure shows the increase in HER current over a $\sim 7.5 \mathrm{~h}$ time period, corresponding to the development of a thin Pt film. The inset shows the final active state after $24 \mathrm{~h}$ of cycling corresponding to a thick Pt film. (a-ii) XPS showing a thick Pt film on the Au foil surface. Au peaks are also visible. In this case the Au:Pt ratio is 0.033 . (a-iii) Schematic model of the Pt-activated Au foil showing a representative thick Pt film on the Au surface from a Pt CE The Pt film may not be uniform and may consist of Pt islands. (b) (b-i) CV (CE = C-paper, $50 \mathrm{mV} / \mathrm{s}$ ) showing deactivation of the Au-Pt system synthesized in (a-i). The inset shows the final deactivated state with little to no HER current. (b-ii) XPS of the deactivated state show a correspondingly higher level of Au present at the surface. This indicates that Au is segregating to the surface, leading to a decrease in HER activity. The increase in Au at the surface leads to an increased Au:Pt ratio of 0.05 as compared to the active state. (b-iii) Schematic model of the deactivated Pt-on-Au foil showing Au segregating to the surface of the Pt layers from the bulk. (c) (c-i) CV $(\mathrm{CE}=\mathrm{C}$-paper, $50 \mathrm{mV} / \mathrm{s})$ showing the reactivation of the previously deactivated sample of $(\mathrm{b}-\mathrm{i})$. The potential was stepped up from $0.57 \mathrm{~V}$ vs NHE to $1.87 \mathrm{~V}$ vs NHE in $0.1 \mathrm{~V}$ increments. For clarity, only three CVs are shown to demonstrate the effect of increasing potential. (c-ii) XPS showing the reactivated sample surface where the Au peaks have decreased again relative to the deactivated state, suggesting Pt has migrated back to the surface. The Au:Pt ratio at the surface was determined to be 0.02 in this reactivated state. (c-iii) Schematic model of the reactivated Pt-on-Au foil, showing the presence of Pt on the outer surface once again.

and $\mathrm{Au} 4 \mathrm{f}$ areas, the peaks were fitted using CasaXPS and the areas determined based on these fits. The ratio of the $\mathrm{Au} 4 \mathrm{f}_{7 / 2}$ to the $\mathrm{Pt}$ $4 \mathrm{f}_{7 / 2}$ for this activated sample is 0.03 .

The presence of $\mathrm{Pt}$ as the dominant surface species was also seen electrochemically when analyzing the HUPD region after activation. As the activity increased over time, the HUPD area for Pt also increased depending on the Pt layer thickness. Figure 2 shows the $\mathrm{CVs}$ before and after the thick Pt layer deposition onto the Au foil, with the inset showing the HUPD region for Pt corresponding to the last $\mathrm{CV}$. The HER current is normalized to the $\mathrm{Au}$ reduction peak area $\left(2.3 \mathrm{~cm}^{2}\right)$ for the clean Au foil, and to the Pt-HUPD areas for the active state CVs $\left(4.5 \mathrm{~cm}^{2}\right)$. As a result of activation, the Au reduction peak signal has decreased significantly from the $2.3 \mathrm{~cm}^{2}$ value to $0.035 \mathrm{~cm}^{2}$ for the thick Pt layer, again suggesting that the $\mathrm{Au}$ foil surface is covered with Pt.

Deactivation process. - Upon deactivation by cycling in a narrow potential window $(-0.09$ to $+0.47 \mathrm{~V}$ vs NHE) with an inert C-paper CE (Fig. 1b), the HER activity decreases back to the origi- nal activity of the clean Au foil (highlighted in the inset, showing final CV), suggesting that $\mathrm{Pt}$ is no longer the dominant surface species having migrated away from the surface. Au would then be present as the topmost surface layer. In general, because XPS does not probe only the topmost surface layer, but has an effective probing depth of $\sim 20$ to $30 \AA$ in this system, it can be difficult to detect the presence of Au which may not be more than $1 \mathrm{ML}$. However, as can be seen from the XPS spectra of Fig. 1b, there is an increase in the Au $4 \mathrm{f}$ signal compared to the XPS spectra of Fig. 1a. The Au to Pt ratio for the deactivated state $(0.05)$ is $34 \%$ higher than in the initial active state (0.033), suggesting that $\mathrm{Au}$ is indeed present on the surface. This difference is enhanced when the XPS is measured at a glancing angle (see the description in the Experimental section above) as shown in Fig. 3a and b. These glancing angle measurements allow more access to the nearer surface region ( $\sim 10$ to $15 \AA$ ); however, they still do not probe only the very first surface layer.

Up to this point, it is clear that the Au WE can be activated, 


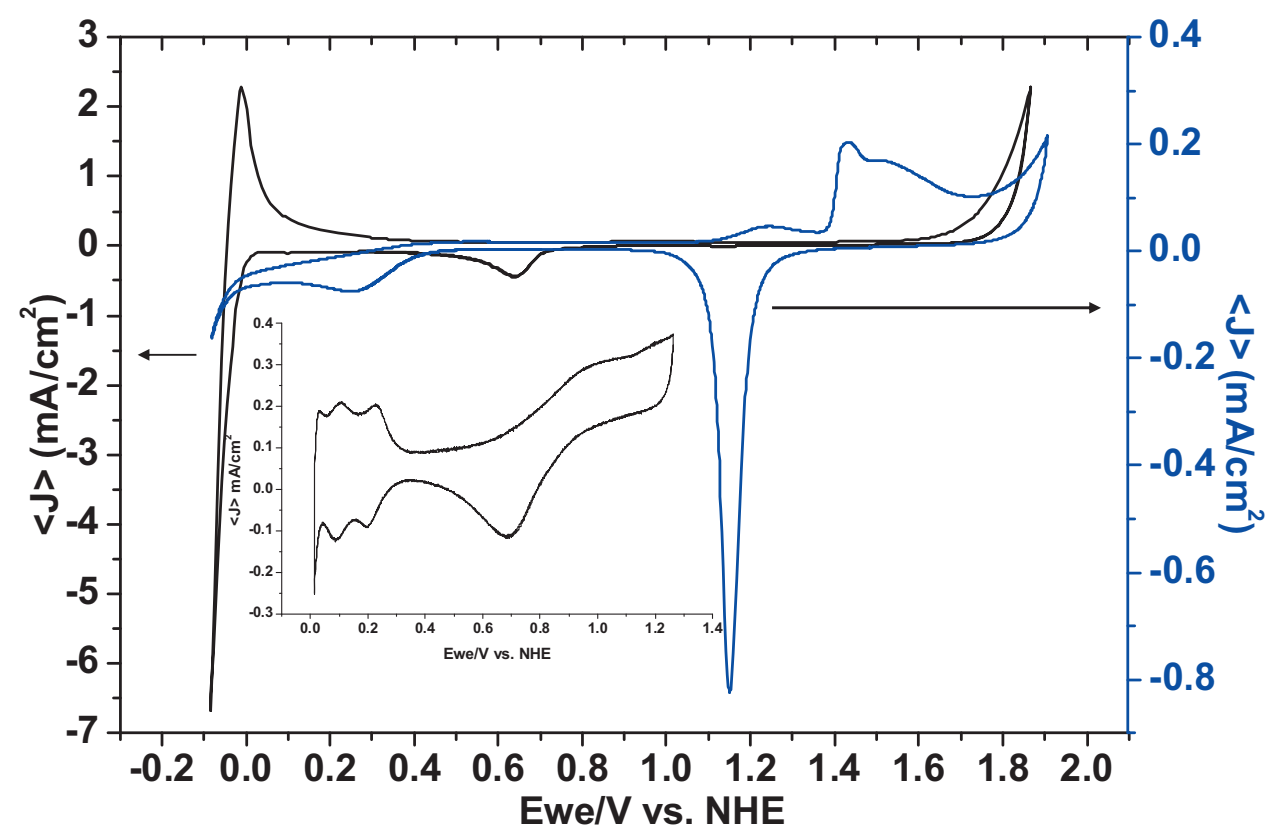

Figure 2. Comparison of $\mathrm{CV}$ s before and after $\mathrm{Pt}$ deposition onto $\mathrm{Au}$ foil. A decrease in the Au reduction peak corresponds to an increase in the HER signal and the development of the Pt HUPD region set. Electrolyte $=0.5 \mathrm{M} \mathrm{H}_{2} \mathrm{SO}_{4}$, scan rate $=50 \mathrm{mV} / \mathrm{s}$ at room temperature.
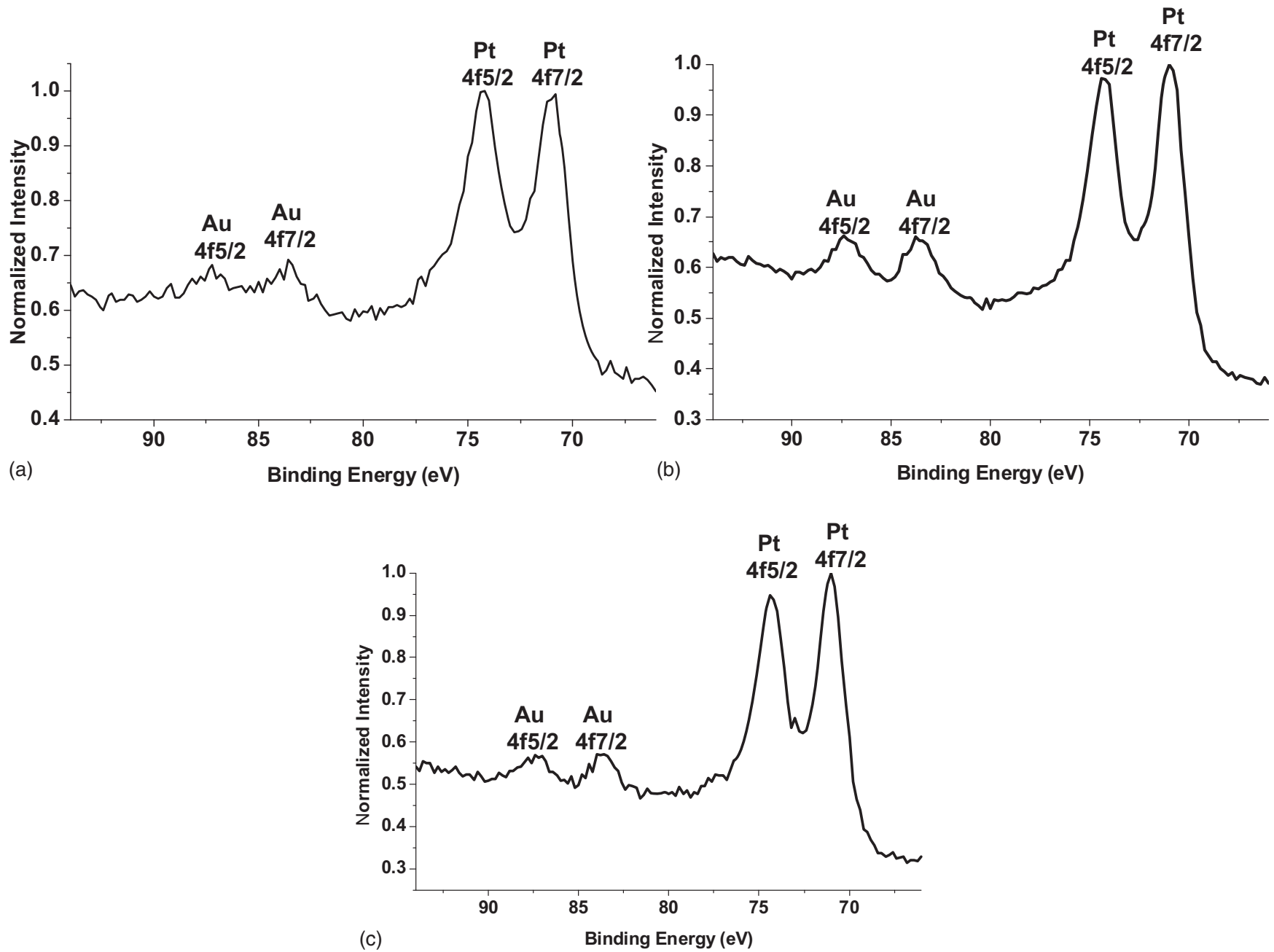

Figure 3. (a) Glancing angle XPS measurements for active thick Pt film sample. Au:Pt ratio is 0.07 based on CasaXPS fitted data. (b) Glancing angle XPS measurements for deactivated thick Pt film sample. Au:Pt ratio is 0.113. (c) Glancing angle XPS measurements for reactivated thick Pt film sample. Au:Pt ratio is 0.087 . 


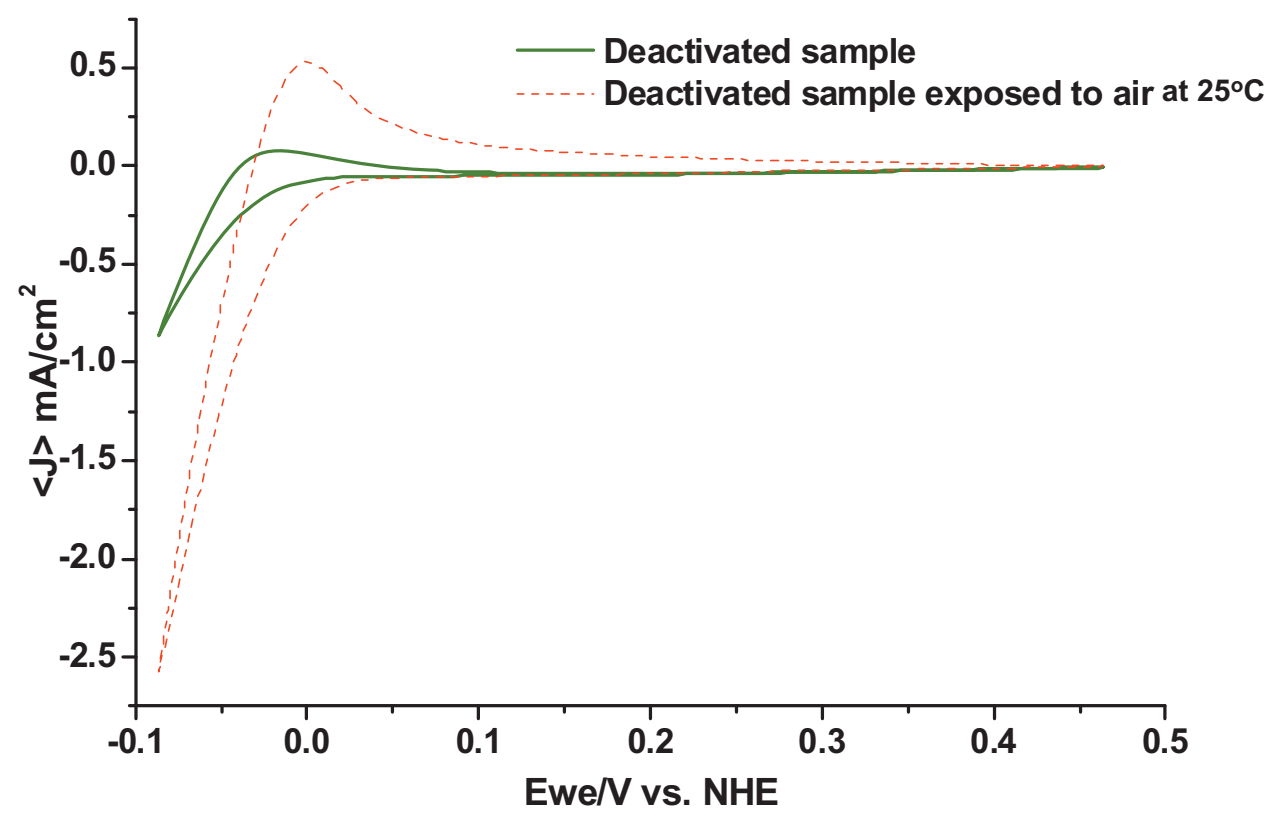

Figure 4. CV of deactivated sample before and after exposure to air. The sample becomes slightly active again due to adsorbate-induced segregation by molecular oxygen pulling Pt back to the surface. However, activity does not reach the same level as when the sample is reactivated using potential sweeps to above $\sim+1 \mathrm{~V}$ vs NHE $\left(0.5 \mathrm{M} \mathrm{H}_{2} \mathrm{SO}_{4}\right.$, scan rate $\left.=50 \mathrm{mV} / \mathrm{s}\right)$.

deactivated, and then reactivated (see the Reactivation section below) based on the CE material and the potential window for CVs. There is also a clear correlation between activity and the surface Au: Pt ratios as determined by XPS; i.e., decreased Pt signal by XPS results in lower activity. The question is, what is the pathway by which the amount of surface Pt decreases relative to $\mathrm{Au}$ ? We have identified three potential pathways for deactivation:

1. Pt could be dissolving into the electrolyte.

2. Some unidentified species in the solution could be depositing itself onto the Pt surface (i.e., a contaminant from the electrolyte or ions/atoms from the CE).

3. Pt could be migrating into the bulk of the WE sample as $\mathrm{Au}$ migrates to the surface.

In examining the first possibility, Pt dissolution into the electrolyte, we conclude that this is not a likely source of Pt removal because the anodic potential applied to the WE during deactivation (Pton-Au sample) never exceeded $+0.47 \mathrm{~V}$ vs NHE, which is well below the dissolution potential of Pt bulk $\left(+1.18 \mathrm{~V}\right.$ vs NHE). ${ }^{12}$ It is possible that the dissolution potential for $\mathrm{Pt}$ can be lowered when $\mathrm{Au}$ is present as calculated by Greeley et al., ${ }^{31}$ however, the change ( $\sim-0.25 \mathrm{~V})$ is still outside the potential window in which the experiment was performed.

The second possibility, contamination, is also unlikely but cannot be completely ruled out. We, in general, avoided the use of a $\mathrm{Au} \mathrm{CE}$ to prevent a metal dissolution-deposition process similar to that observed with Pt CEs. This is why the C-paper CE was utilized in demonstrating the deactivation process. A substantial $\mathrm{C}$ 1s signal was evident on both activated and deactivated samples, making it difficult to conclude whether or not C-based contamination from the $\mathrm{CE}$ played a role in the experiment. But, this large $\mathrm{C} 1 \mathrm{~s}$ signal is not surprising as it is well-known that adventitious $\mathrm{C}$ naturally deposits itself on samples exposed to atmospheric air. Although XPS studies for contamination were inconclusive, the XPS overview spectra of the WE surface showed no signs of contamination from foreign elements. This is further corroborated by the fact that, if contamination was the source of deactivation, we might expect that pure $\mathrm{Pt}$ would deactivate in the same manner. This, however, does not occur. When a pure Pt WE (Pt film electrodeposited onto FTO) was exposed to the same deactivation conditions as the Pt-Au system, the activity increased initially and stabilized due to cleaning the surface of contaminants present prior to being placed in the electrochemical cell. Nevertheless, it is difficult to rule out whether or not there is an ionic species present in the solution that causes deactivation of the Pt-on-Au system, but we have no evidence of its existence.

The third possibility is the most likely mechanism: migration of Pt into the bulk of the sample and Au to the surface as demonstrated by Pedersen et al. in studying CO reactivity. ${ }^{15}$ XPS data indicate the presence of $\mathrm{Au}$ on the surface of the sample regardless of the deactivation method ( $\mathrm{Au} \mathrm{CE}, \mathrm{C}$-paper $\mathrm{CE}$, or separate compartmentalized electrolytes). The thermodynamic driving forces that lead to the segregation of $\mathrm{Au}$ to the surface suggest the formation of an overlayer structure consisting of no more that $1 \mathrm{ML}$ of Au. However, as shown in the supplementary material of Greeley et al., ${ }^{5}$ there are various surface alloy structures that can lead to the degradation of HER relative to pure bulk Pt. For the Pt on bulk Au system, DFT calculations show, with $1 / 3 \mathrm{ML}$ coverage, the HER based on the $\Delta G_{\mathrm{H}}$ for the adsorption of hydrogen is close to that of pure $\mathrm{Pt}$. However, the HER decreases with a coverage of $2 / 3 \mathrm{ML}$ of $\mathrm{Pt}$ on $\mathrm{Au}$. The decrease is much larger when considering 1 full $\mathrm{ML}$ of $\mathrm{Pt}$ on bulk $\mathrm{Au}$ while the activity is reduced even further for $1 \mathrm{ML}$ of $\mathrm{Au}$ on bulk Pt. Thus, for coverages above 1/3 ML, the HER activity would be significantly compromised relative to pure Pt. For the deactivated sample, it is difficult to know which structure is present.

The XPS data of Fig. 1b-ii show a larger Au to Pt ratio on the surface of a deactivated sample in comparison to an active sample, an effect that is somewhat mitigated due to the chemical potential of molecular oxygen in air, which itself causes adsorbate-induced surface segregation. To demonstrate this, we pulled a deactivated sample out of the electrolyte (i.e., exposed it to air), and then transferred it into a new clean electrolyte with no other treatment; the sample immediately becomes active again, albeit not as active as it first was in its original active state (see Fig. 4). This occurs for both thin and thick Pt "deactivated" samples; they start off with Au migrating to the surface but only small amounts of Pt (forming 1/3 ML or less) need to reach the surface once again to reactivate the sample. This picture is consistent with the XPS spectra of Fig. 1b-i and 1b-ii, which show a marked increase in the surface content of $\mathrm{Au}$ relative to a thick Pt film upon deactivation. For the thin Pt film, using XPS to differentiate between the activated and deactivated state is challenging due to significant overlap of the $\mathrm{Au}$ 4f $\alpha 3$ and $\alpha 4$ peaks as well as nonuniformities in the Pt layer. It is also possible that, upon pulling the sample out of solution and exposing it to air, a surface alloy is formed. Although the amount of $\mathrm{Au}$ on the 

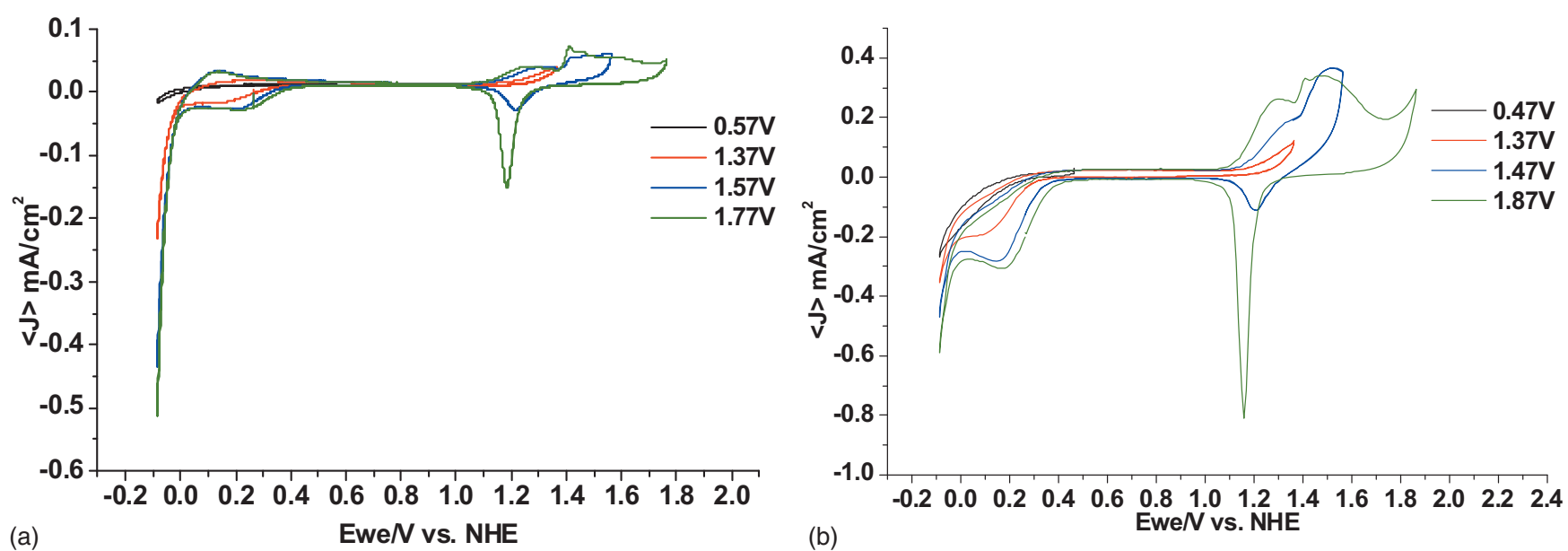

Figure 5. (a) Clean Au foil CVs where the CV max voltage was increased in $100 \mathrm{mV}$ increments. Au CE was used. Electrolyte possibly contaminated with Pt $\left(0.5 \mathrm{M} \mathrm{H}_{2} \mathrm{SO}_{4}\right.$ electrolyte, $50 \mathrm{mV} / \mathrm{s}$ scan rate). (b) Clean Au foil CVs where the $\mathrm{CV}$ maximum voltage was increased in $100 \mathrm{mV}$ increments. C-paper CE was used. Electrolyte possibly contaminated with $\mathrm{Pt}\left(0.5 \mathrm{M} \mathrm{H}_{2} \mathrm{SO}_{4}\right.$ electrolyte, $50 \mathrm{mV} / \mathrm{s}$ scan rate).

surface increases relative to Pt in the deactivated state, for a nonuniform thin Pt film the difference between the two species is difficult to delineate.

The rate of deactivation appeared to be dependent on the thickness of the Pt layer. The thin Pt film took less time to deactivate than the thick Pt film. This correlates with the migration time necessary for $\mathrm{Au}$ to come to the surface, suggesting that it should take longer for a thicker Pt layer to deactivate.

Reactivation process.- Once the sample is in the deactivated state, it can again be reactivated. This was done while the $\mathrm{CE}$ was an inert material such as $\mathrm{Au}$ or $\mathrm{C}$-paper, not Pt. The WE was then placed in an electrochemical cell that had not seen Pt. The maximum potential during cycling was then increased further anodically in $100 \mathrm{mV}$ increments from $+0.57 \mathrm{~V}$ vs $\mathrm{NHE}$ to $+1.87 \mathrm{~V}$ vs NHE which is well above the Pt dissolution potential ( $\sim 1.18 \mathrm{~V}$ vs NHE). This process is shown in Fig. 1c. For clarity, only three of the potentials analyzed are shown in Fig. 1c-i. The inset shows the final reactivated $\mathrm{CV}$. As mentioned above, the deactivated sample can also be partly reactivated by just exposing it to air, where oxygen will pull Pt back to the surface. However, this never led to a complete reactivation, back to the original activity of the first activated sample.

Upon ramping the potential to greater than $+1 \mathrm{~V}$ vs NHE, the sample reactivates to the same HER currents displayed by the sample prior to deactivation $\left(\sim 6.5 \mathrm{~mA} / \mathrm{cm}^{2}\right.$ at $-0.09 \mathrm{~V}$ vs NHE). HUPD analysis showed a clear increase in the presence of Pt on the surface of the sample, explaining the reason for the increase in the HER current. XPS data also show that in this case, Pt is certainly on the surface (Fig. 1c-ii). As can be seen in the figure, the $\mathrm{Au}$ to $\mathrm{Pt}$ ratio clearly decreases once again to 0.02 . This effect is emphasized in the XPS glancing angle measurement as shown in Fig. 3c, where the $\mathrm{Au}$ :Pt ratio decreases from 0.113 in the deactivated state to 0.087 in the reactivated state.

To isolate the source of Pt leading to this reactivation in the presence of the same inert CE used for the deactivation process, two experiments were performed. In the first experiment, the deactivated

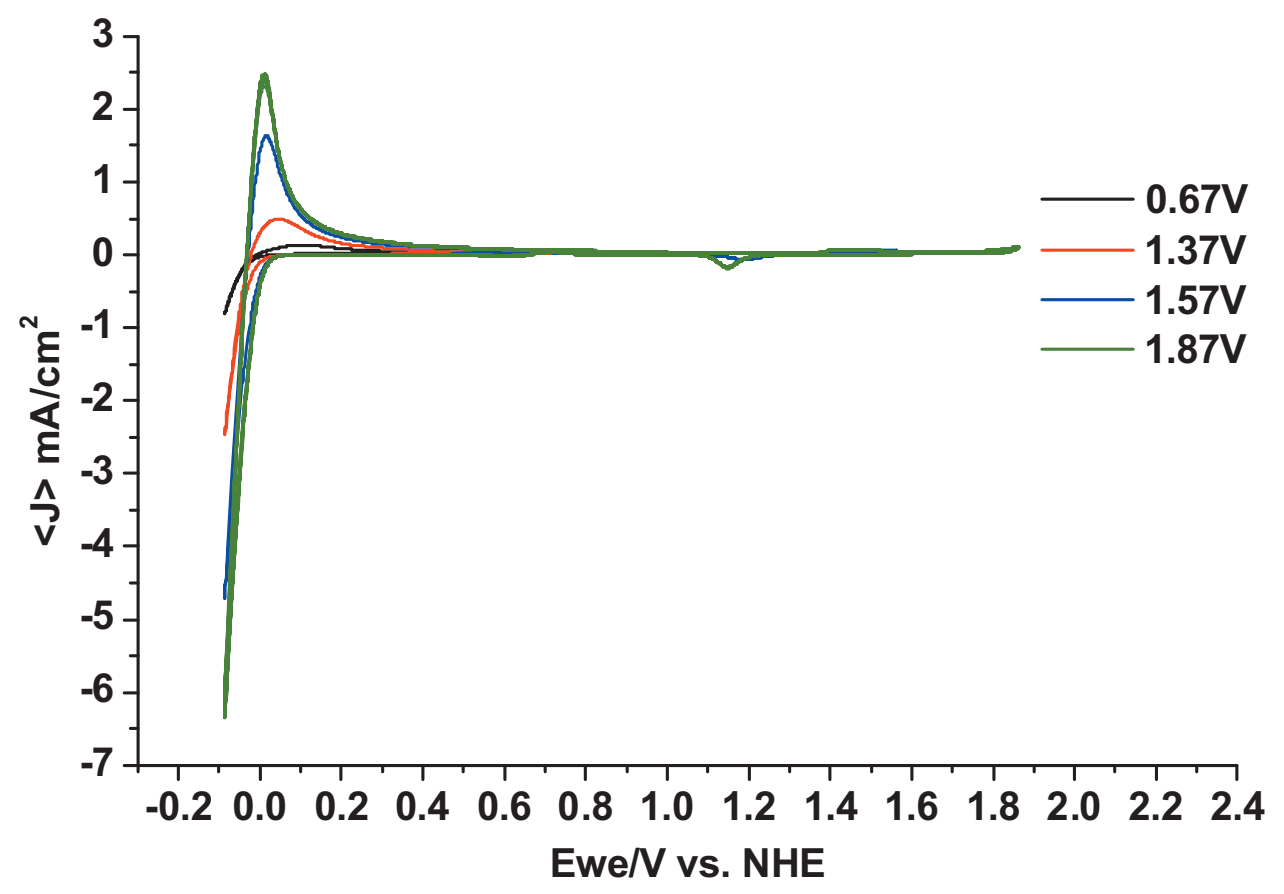

Figure 6. Previously activated Au foil shows enhanced activity as function of potential in a clean electrolyte. Shows activation results from Pt coming to the surface from the sample itself $\left(0.5 \mathrm{M} \mathrm{H}_{2} \mathrm{SO}_{4}\right.$ electrolyte, $50 \mathrm{mV} / \mathrm{s}$ scan rate). 


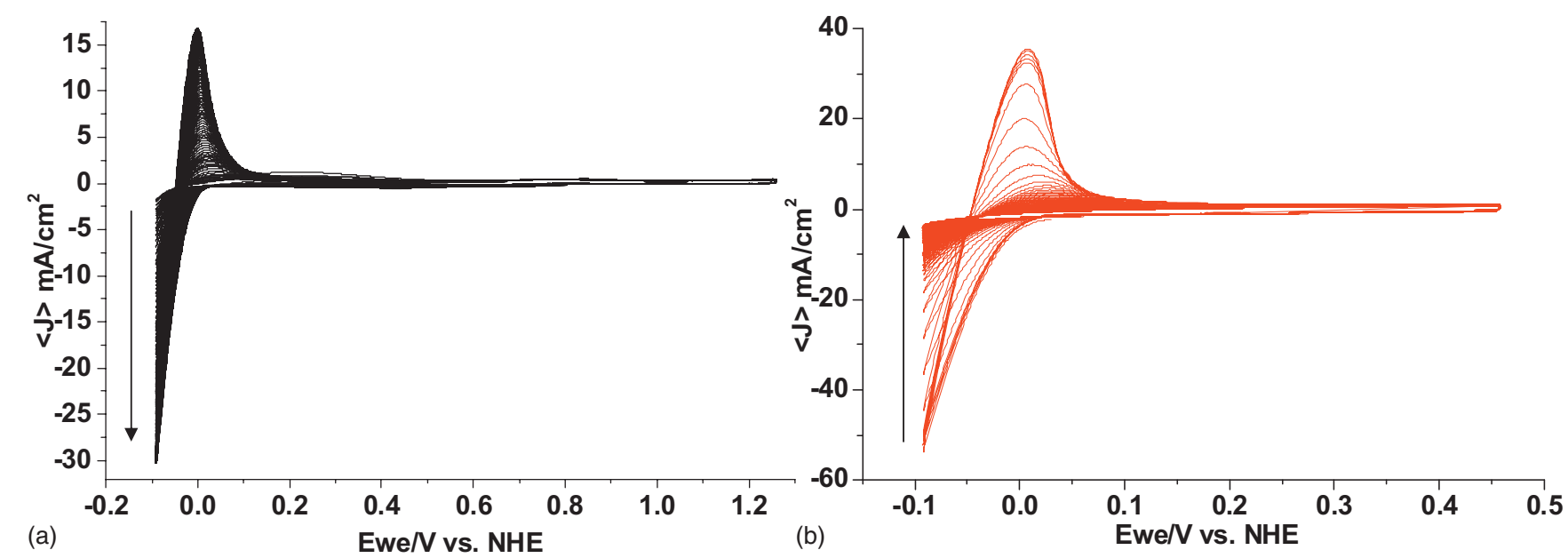

Figure 7. (a) Activation of the Au nanoparticles upon deposition of $\mathrm{Pt}$ from a Pt CE As in the Au foil case, cycling continuously over a time period of $24 \mathrm{~h}$, as seen by sequential CVs, led to the activation (deposition of $\mathrm{Pt}$ ) of the Au nanoclusters. (Electrolyte $=0.5 \mathrm{M} \mathrm{H}_{2} \mathrm{SO}_{4}$, scan rate is $50 \mathrm{mV} / \mathrm{s}$.) (b) Deactivation of the Au nanoparticles upon cycling with a Au CE Again, as in the case of the bulk Au foil, cycling in a narrower potential window (-0.1 to $+0.47 \mathrm{~V}$ vs NHE) while using an inert $\mathrm{CE}$ such as Au led to HER deactivation due to Au migrating to the surface of the Pt-on-Au system.

WE sample was replaced with a completely clean Au foil WE while the electrolyte used for the deactivation process was reused. If the aqueous solution was in fact contaminated with Pt, we would expect to see an activation process occur. The $\mathrm{CE}$ was also a completely $\mathrm{Au}$ foil or C-paper. The potential was slowly increased from +0.57 vs NHE, where the sample is not active (i.e., it shows activity of pure $\mathrm{Au}$ ), to potentials above $+1 \mathrm{~V}$ vs NHE. As can be seen in Fig. 5a and $b$, there is not much increase in the HER current regardless of what $\mathrm{CE}$ is used (Au foil or C-paper, respectively). The slight increase in activity is an order of magnitude smaller than that observed in previous experiments with a Pt CE, suggesting, not surprisingly, that the electrolyte may have contained only very small amounts of Pt.

In the second experiment, the deactivated sample remained the WE and the electrolyte was exchanged for a fresh electrolyte purged with nitrogen, ensuring that there could be no Pt coming from the electrolyte. The $\mathrm{CE}$ was replaced by a $\mathrm{Au}$ foil that had never been exposed to Pt. Again, the potential was increased from +0.57 vs NHE to potentials above $+1 \mathrm{~V}$ vs NHE. To minimize air exposure and inadvertent reactivation due to oxygen from the air, the original WE sample was flushed with deaerated electrolyte while the setup was rearranged. Figure 6 shows reactivation to the levels observed prior to deactivation. This clearly shows that the Pt leading to reactivation of the sample is coming from the sample itself because this is the only source of Pt present in the system.

The potential-dependent behavior of this system suggests that the surface is very dynamic. The inherent surface free energy of the Au is lower than Pt, causing it to be present at the surface, while Pt diffuses into the bulk, when no external driving forces are present to keep it on the surface. In this case the potential acts as that external driving force, changing the surface thermochemistry to the point where $\mathrm{Pt}$ is stabilized at the surface. Adsorption of $\mathrm{OH}$ groups from the electrolyte could play a critical role in bringing Pt back to the surface at potentials near or above $+1 \mathrm{~V}$ vs NHE.

Au nanoclusters (inverse micelle).- The same type of activation-deactivation-reactivation behavior was observed in a threeelectrode electrochemical cell for nanoclusters of the Pt-on-Au system. As stated in the Experimental section above, the initial size of these clusters was $1.6 \pm 0.2 \mathrm{~nm}$ as determined by TEM (not shown). However, upon heat-treatment, the size increased significantly and was estimated to be on the order of $10 \mathrm{~nm}$. The activity of the Au nanoparticles on C-paper was monitored during the deposition of Pt onto the surface from a Pt CE As can be seen in Fig. 7a, the activity for HER increases with increasing the concentration of $\mathrm{Pt}$ on the Au nanoparticle electrode surface.

After deposition of Pt onto the sample, the core-shell-like Pton-Au system was monitored for stability by replacing the Pt mesh $\mathrm{CE}$ with a $\mathrm{Au}$ foil $\mathrm{CE}$ and replacing the electrolyte with clean electrolyte. Once again, upon cycling in the narrow potential window where $\mathrm{Au}$ would likely become the dominant surface species, significant degradation of the HER signal was observed. This is shown in Fig. 7b. However, if the potential was increased above $+1.0 \mathrm{~V}$ vs NHE with the Au CE present, the system would reactivate once again. In the same manner as the bulk Au foil system, the deactivation and reactivation processes could be repeated cyclically.

The dynamics of the small clusters varied relative to the other two systems, possibly due to the enhanced surface to volume ratio. These differences warrant possible further investigation.

E-TEK Au-Pt system fuel cell measurements.- The E-TEK AuPt sample was studied using a fuel cell setup as described above. The same types of electrochemical experiments were performed as in the three-electrode electrochemical cell for the bulk Au foil. The E-TEK sample was utilized as the WE, the IRD standard Pt catalyst as the $\mathrm{CE}$, and NHE as the reference electrode. The sample was

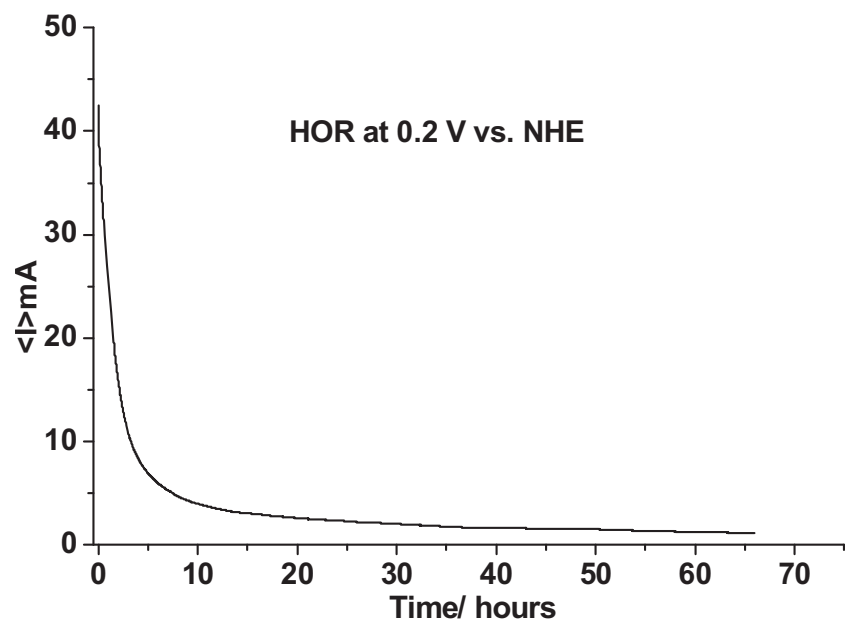

Figure 8. Deactivation of HOR by maintaining the WE (Pt on E-TEK Au) at $+0.2 \mathrm{~V}$ vs NHE. 


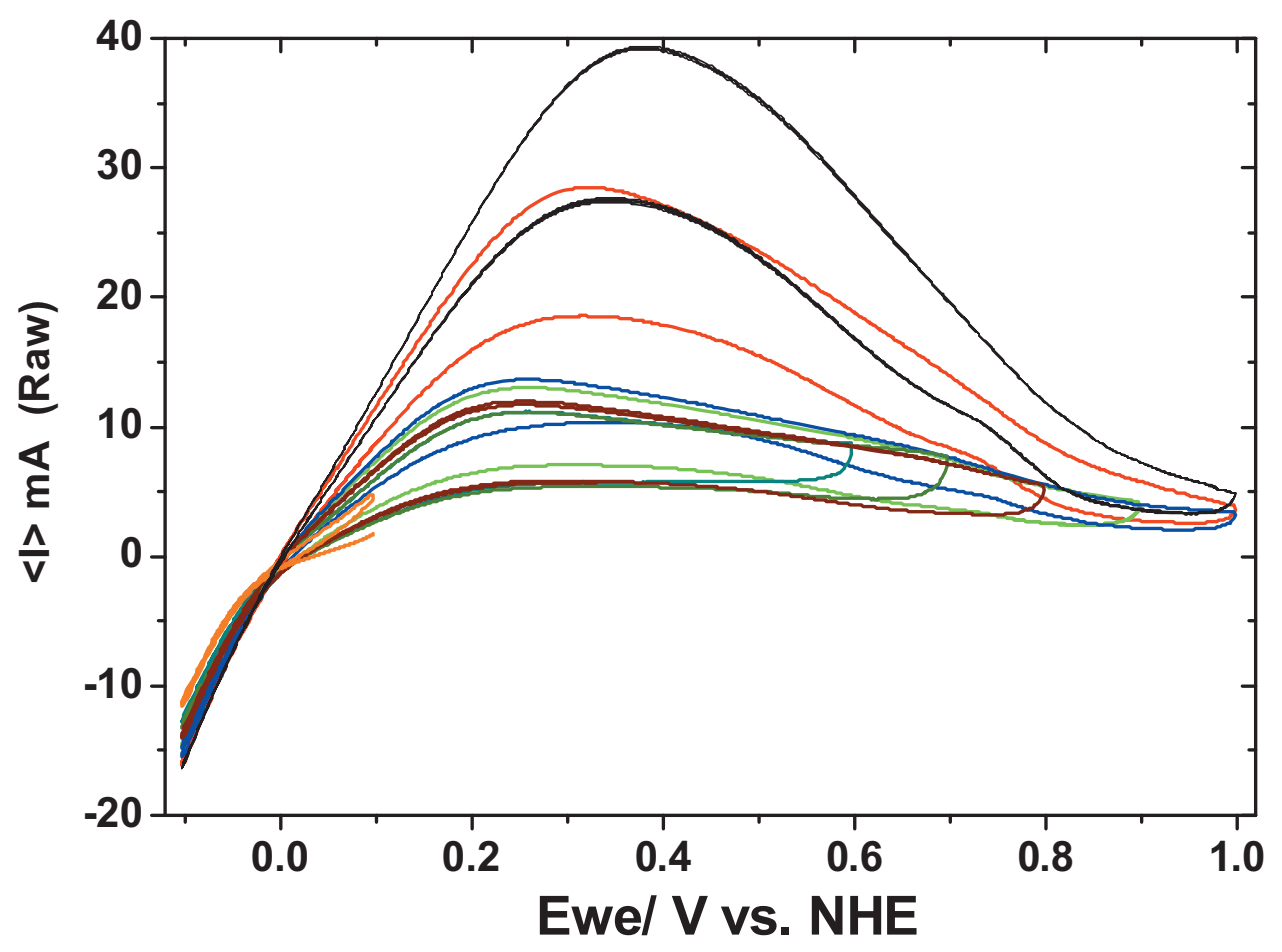

Figure 9. Reactivation $\mathrm{CV}$ of $\mathrm{Pt}$ on E-TEK Au for HOR measured in the fuel cell at $5 \mathrm{mV} / \mathrm{s}$. The maximum anodic potential is increased from $+0.1 \mathrm{~V}$ (orange) to $+0.6 \mathrm{~V}$ (turquoise), $+0.7 \mathrm{~V}$ (green), $+0.8 \mathrm{~V}$ (brown), +0.9 V (light green), $+1.0 \mathrm{~V}$ (note transitions from blue curve, to red curve to black curve all at $+1.0 \mathrm{~V}$ ) When holding the potential at $+1.0 \mathrm{~V}$, the HOR continues to increase. This shows that the reactivation potential is the same in the fuel cell: $\sim+1 \mathrm{~V}$ vs NHE for HOR. already known to be active based upon the CVs performed during the Pt deposition in the three-electrode electrochemical cell. The sample could then be deactivated, just as in the three-electrode cell configuration, by holding the potential at $0.2 \mathrm{~V}$ vs NHE (Fig. 8).

The sample could then be reactivated once again by cycling above $+1 \mathrm{~V}$ vs NHE. The reactivation potential onset was measured in the same manner as in the three-electrode cell where the potential was cycled from $+0.1 \mathrm{~V}$ vs NHE to $+1 \mathrm{~V}$ vs NHE. Figure 9 shows that the reactivation potential occurs once again at $+1.0 \mathrm{~V}$ vs NHE for both HER and HOR. This reactivation-deactivation process could be repeated cyclically depending on the applied potential. In the reactivation case (seen more abruptly in Fig. 10), Pt was present on the surface. The only source of Pt present under these fuel cell conditions is the WE sample itself. Although it is technically possible to deposit Pt ions through a Nafion membrane as demonstrated by Chou et al., ${ }^{32}$ this would not occur under the conditions with which we are operating our fuel cell. Thus, Pt from the CE is unlikely to contaminate the surface of the WE, supporting the mechanism of Au migration from the sample itself to the surface replacing Pt. As in the three-electrode cell, a surface exchange reaction occurs, leading to Pt diffusing into the bulk under mild potential conditions and subsequently diffusing back to the surface when potentials $\geqslant$ $+1 \mathrm{~V}$ vs NHE are applied.

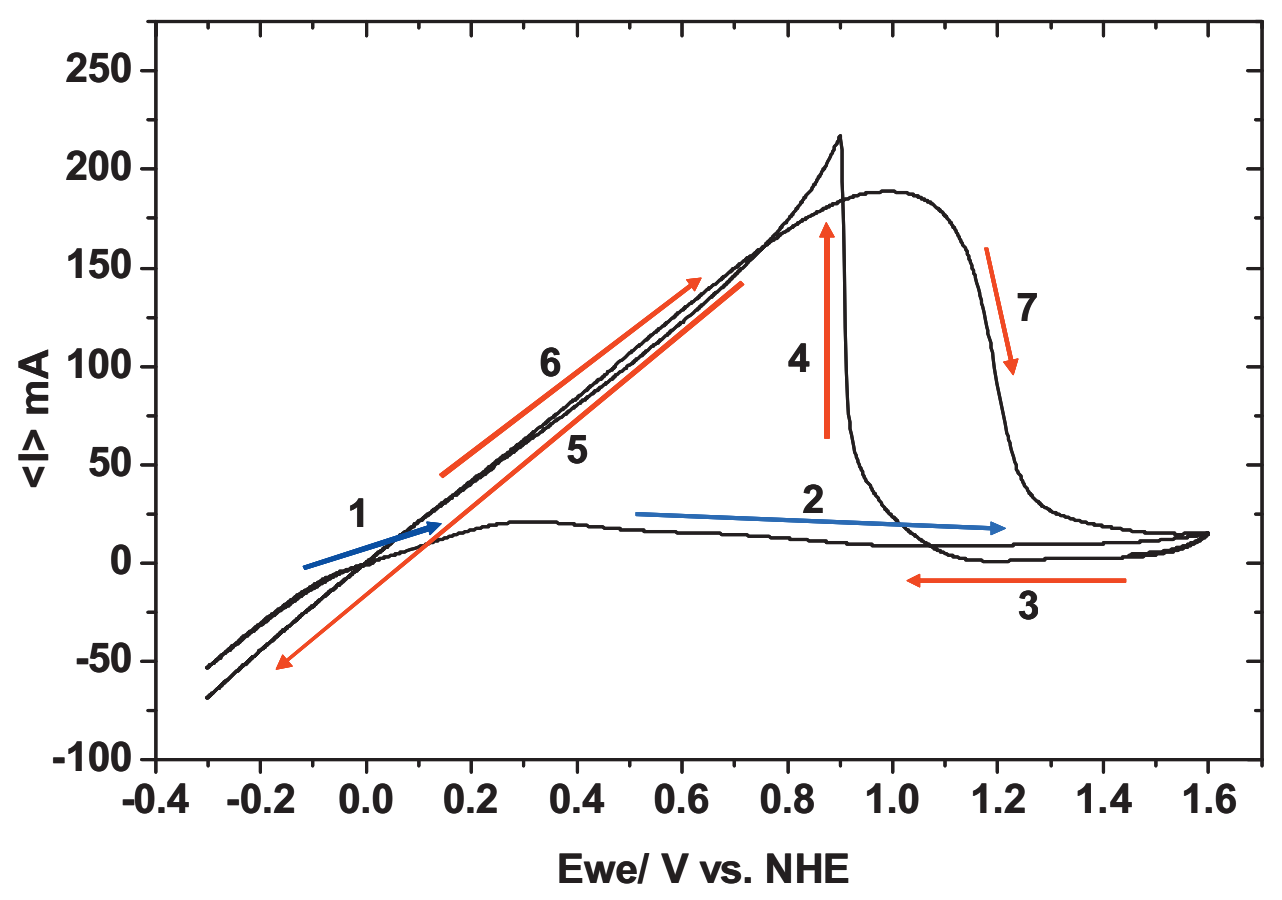

Figure 10. CV performed in a fuel cell at $5 \mathrm{mV} / \mathrm{s}$ showing the cyclic deactivation and reactivation of HER/HOR as a function of potential. Reversibility of HER/ HOR suggests that $\mathrm{Pt}$ is being drawn out from within the sample. Path 1: Initial sweep moving anodially, path 2: Continued anodic sweep showing little to no HOR activity, path 3: Cathodic sweep begins, path 4: Abrupt onset of HOR after having been at potentials $>+1 \mathrm{~V}$ vs NHE, path 5: Cathodic sweep toward HER, paths 6 and 7: Anodic sweeps showing HOR and continuation of the electrochemical processes. 


\section{Conclusions}

We have shown that for the Pt-on-Au system, surface exchange reactions play an important role in determining the dominant materials species available for electrocatalytic reactions such as HER and HOR. The surface composition was shown to be potentialdependent, with an activation potential of $\sim+1 \mathrm{~V}$ vs NHE. This positive potential corresponded to $\mathrm{Pt}$ residing on the surface and subsequently to an enhanced overall activity for the system. At potentials cathodic of $+1 \mathrm{~V}$ vs NHE, XPS analysis showed that Au was present at the surface. Under these conditions, the HER and HOR activity decreased significantly to a deactivated state. Following deactivation, the system could be reactivated once again by cycling to potentials anodic of the Pt dissolution potential. The behavioral trends for this Pt-Au alloy/core-shell system was the same for $\mathrm{Pt}$ on bulk $\mathrm{Au}$ foil, on Au nanoparticles analyzed in a three-electrode electrochemical cell, as well as in a PEM fuel cell electrochemical evaluation. The mechanism for this phenomenon is attributed to the lower surface energy of $\mathrm{Au}$ relative to $\mathrm{Pt}$, causing $\mathrm{Au}$ to reside preferentially on the surface under conditions where there are no other competing processes. This leads to a system that is deactivated for both HER and HOR. However, when the chemical potential of adsorbates (such as oxygen or $\mathrm{OH}$ groups onto $\mathrm{Pt}$ ) is dominant over segregation energies, $\mathrm{Pt}$ is again restored to the surface, leading to HER/HOR reactivation.

In designing materials for electrocatalysis, particularly alloys, or core-shell systems, it is important to consider the surface free energies of each component material. It is desirable to develop a system that minimizes the use of $\mathrm{Pt}$ as a material, while at the same time maintaining the same or better activity for a given reaction. Utilizing a core material with a greater surface energy than $\mathrm{Pt}$, as well as a chemical inertness inhibiting segregation, would minimize or possibly eliminate this potential-dependent surface exchange reaction and keep Pt as a thin skin dominant on the surface.

\section{Acknowledgments}

Center for Integrated Nanoparticle Functionality is funded by the National Danish Research. This project was also funded by F. C. Anode. T. F. J. acknowledges the H. C. Ørsted Fellowship for support. J. B. was supported by the Danish Strategic Research Council. The authors acknowledge John Larsen for XPS measurements, and Klas Andersson, Lone Bech, and Ifan Stephens for helpful discussions.
Technical University of Denmark assisted in meeting the publication costs of this article.

\section{References}

1. J. Zhang, K. Sasaki, E. Sutter, and R. R. Adzic, Science, 315, 220 (2007).

2. J. C. Davies, J. Bonde, A. Logadottir, J. K. Norskov, and I. Chorkendorff, Fuel Cells, 5, 429 (2005).

3. H. A. Gasteiger, N. Markovic, P. N. Ross, and E. J. Cairns, J. Phys. Chem., 98, 617 (1994).

4. H. F. Oetjen, V. M. Schmidt, U. Stimming, and F. Trila, J. Electrochem. Soc., 143, 3838 (1996).

5. J. Greeley, T. F. Jaramillo, J. Bonde, I. B. Chorkendorff, and J. K. Norskov, Nature Mater, 5, 909 (2006).

6. J. Greeley and J. K. Norskov, Surf. Sci., 601, 1590 (2007).

7. H. Moller and P. C. Pistorius, J. Electroanal. Chem., 570, 243 (2004).

8. J. H. Choi, K. W. Park, I. S. Park, K. Kim, J. S. Lee, and Y. E. Sung, J. Electrochem. Soc., 153, A1812 (2006).

9. P. Hernandez-Fernandez, S. Rojas, P. Ocon, A. de Frutos, J. M. Figueroa, P. Terreros, M. A. Pena, and J. L. G. Fierro, J. Power Sources, 177, 9 (2008).

10. L. Yang, J. Chen, X. Zhong, K. Cui, Y. Xu, and Y. Kuang, Colloids Surf., A, 295, 21 (2007).

11. D. Zhao and B. Q. Xu, Phys. Chem. Chem. Phys., 8, 5106 (2006).

12. J. Van Muylder, N. De Zoubov, and M. Pourbaix, in Atlas of Electrochemical Equilibria in Aqueous Solutions, M. Pourbaix, Editor, p. 378, Pergamon Press, Oxford (1966).

13. K. A. Friedrich, F. Henglein, U. Stimming, and W. Unkauf, Colloids Surf., A, 134, 193 (1998).

14. K. A. Friedrich, F. Henglein, U. Stimming, and W. Unkauf, Electrochim. Acta, 45 3283 (2000).

15. M. O. Pedersen, S. Helveg, A. Ruban, I. Stensgaard, E. Laegsgaard, J. K. Norskov, and F. Besenbacher, Surf. Sci., 426, 395 (1999).

16. A. Ruban, B. Hammer, P. Stoltze, H. L. Skriver, and J. K. Norskov, J. Mol. Catal. A: Chem., 115, 421 (1997).

17. A. V. Ruban, H. L. Skriver, and J. K. Norskov, Phys. Rev. B, 59, 15990 (1999).

18. J. Nerlov, S. Sckerl, J. Wambach, and I. Chorkendorff, Appl. Catal., A, 191, 97 (2000).

19. H. Angerstein-Kozlowska, B. E. Conway, and W. B. A. Sharp, J. Electroanal Chem. Interfacial Electrochem., 43, 9 (1973).

20. N. M. Markovic and P. N. Ross, Surf. Sci. Rep., 45, 121 (2002).

21. A. Hamelin, J. Electroanal. Chem., 407, 1 (1996).

22. A. Hamelin and A. M. Martins, J. Electroanal. Chem., 407, 13 (1996).

23. J. P. Hoare, J. Electrochem. Soc., 131, 1808 (1984).

24. J. P. Wilcoxon and B. L. Abrams, Chem. Soc. Rev., 35, 1162 (2006).

25. J. P. Wilcoxon, J. E. Martin, and P. Provencio, Langmuir, 16, 9912 (2000).

26. J. P. Wilcoxon, R. L. Williamson, and R. Baughman, J. Chem. Phys., 98, 9933 (1993).

27. G. Schmid, Endeavour, 14, 172 (1990).

28. D. Chakraborty, H. Bischoff, I. Chorkendorff, and T. Johannessen, J. Electrochem. Soc., 152, A2357 (2005).

29. S. B. Brummer, J. Electrochem. Soc., 112, 633 (1965).

30. P. Malachesky, R. Jasinski, and B. Burrows, J. Electrochem. Soc., 114, 1104 (1967).

31. J. Greeley and J. K. Norskov, Electrochim. Acta, 52, 5829 (2007).

32. J. Chou, S. Jayaraman, A. D. Ranasinghe, E. W. McFarland, S. K. Buratto, and H. Metiu, J. Phys. Chem. B, 110, 7119 (2006). 